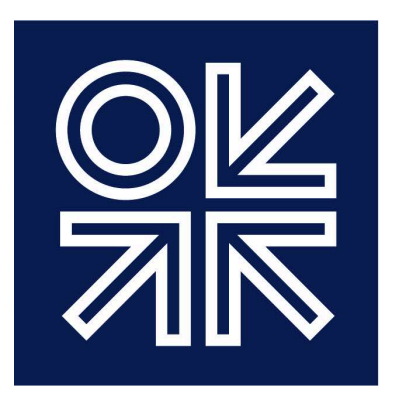

THE OXFORD INSTITUTE FOR ENERGY STUDIES

November 2016

\title{
Unravelling the US Shale Productivity Gains
}

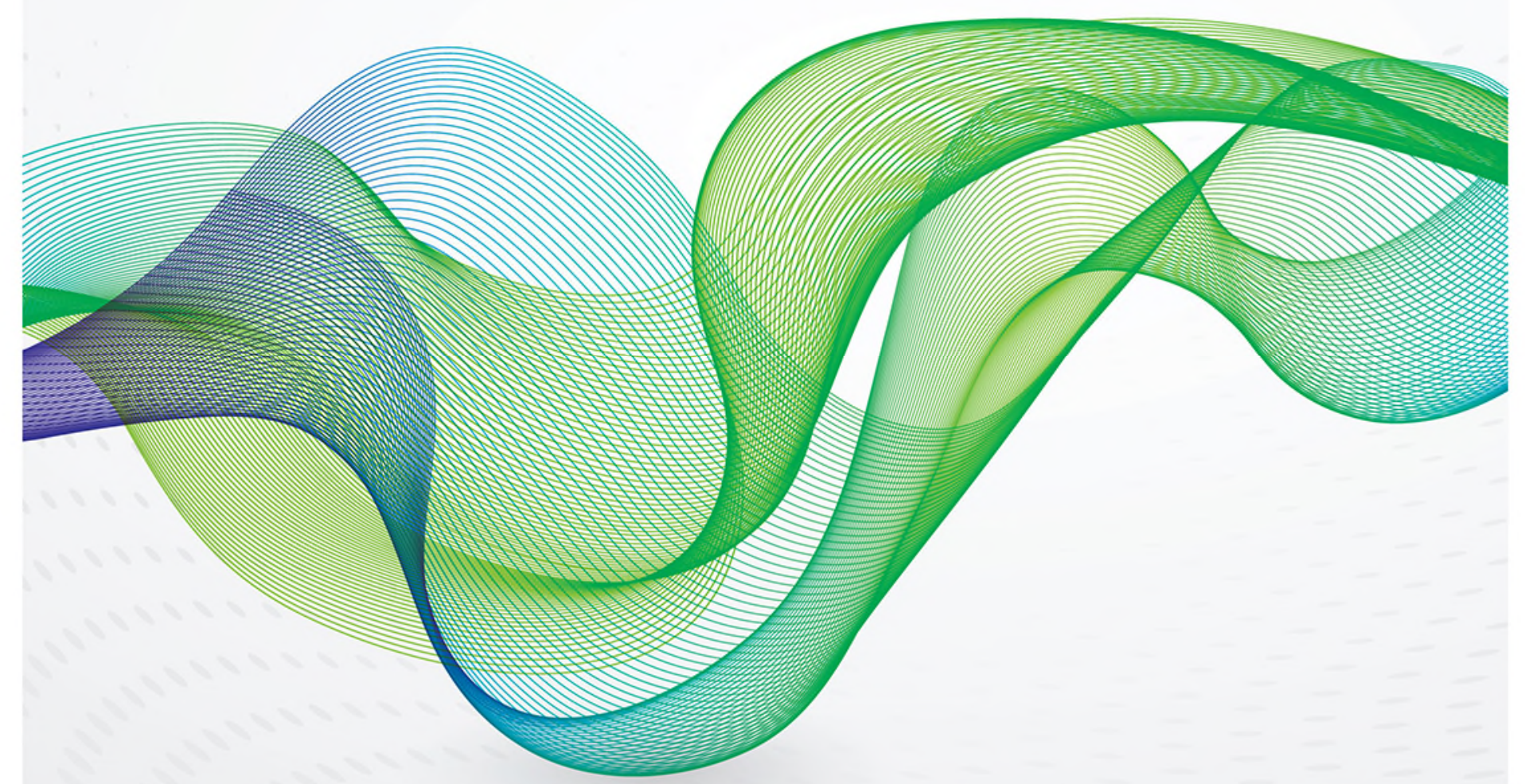



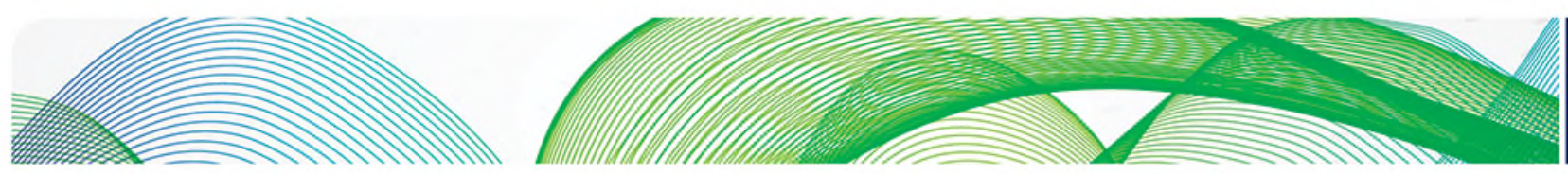

\section{애잦}

The contents of this paper are the authors' sole responsibility. They do not necessarily represent the views of the Oxford Institute for Energy Studies or any of its members.

Copyright @ 2016

Oxford Institute for Energy Studies

(Registered Charity, No. 286084)

This publication may be reproduced in part for educational or non-profit purposes without special permission from the copyright holder, provided acknowledgment of the source is made. No use of this publication may be made for resale or for any other commercial purpose whatsoever without prior permission in writing from the Oxford Institute for Energy Studies.

ISBN 978-1-78467-072-6 

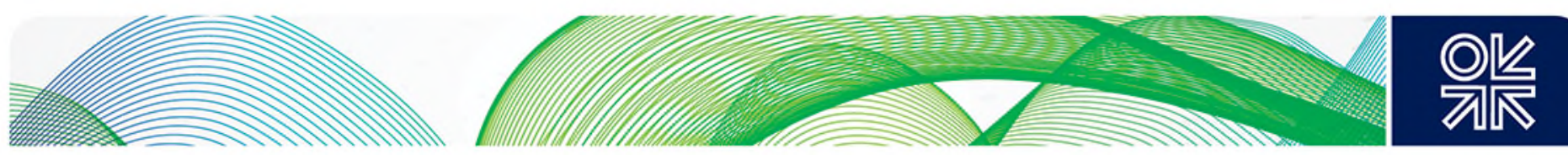

\section{Contents}

1. Introduction 1

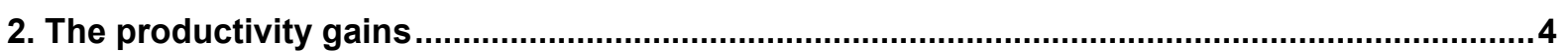

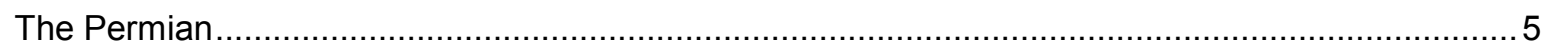

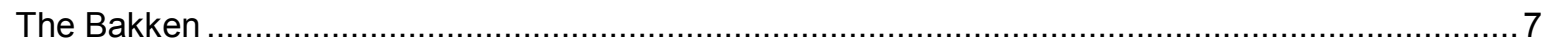

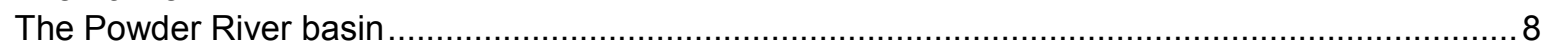

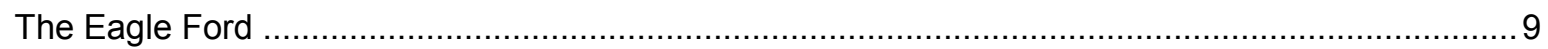

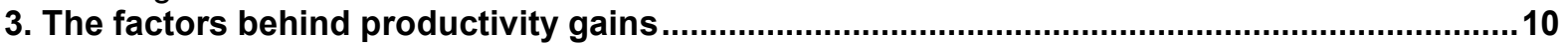

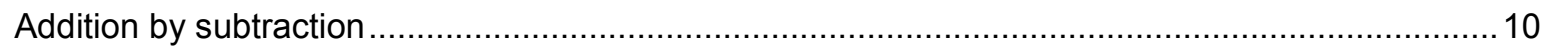

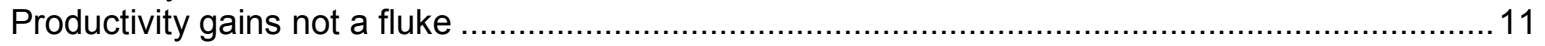

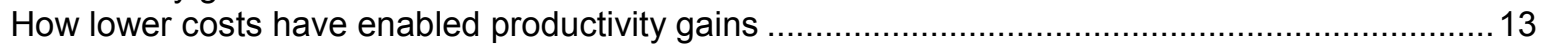

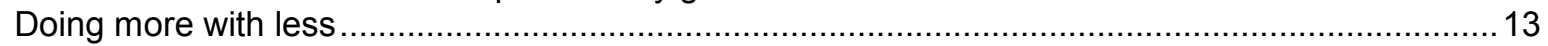

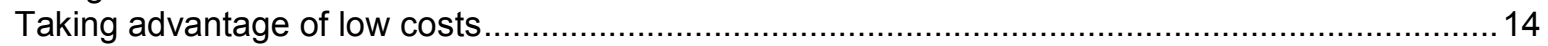

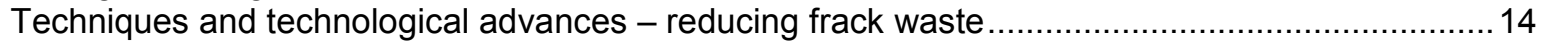

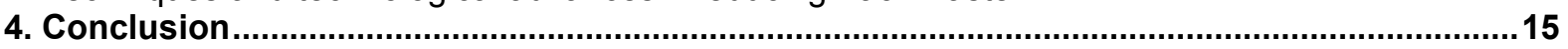

\section{Figures}

Figure 1: EUR growth in the Permian, Williston (Bakken), and Powder River basins (2014-16) .........1

Figure 2: Aggregated oil decline curve for horizontal Permian, Williston, and Powder River wells (2011-16)

Figure 3: Oil production in four plays (2013-16)

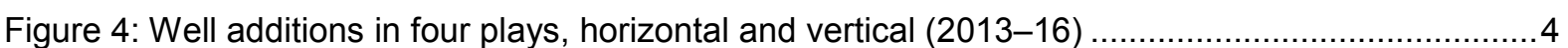

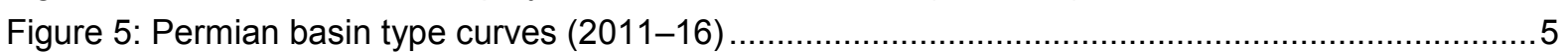

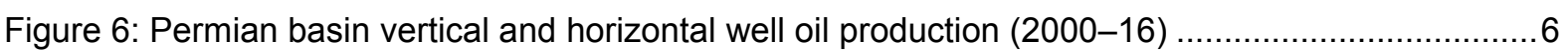

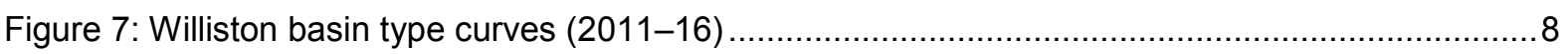

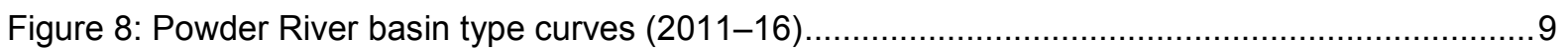

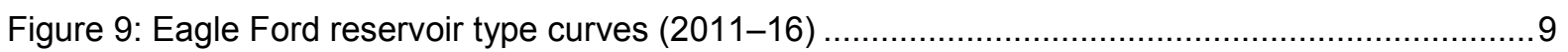

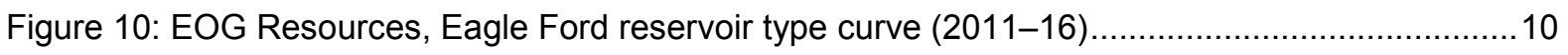

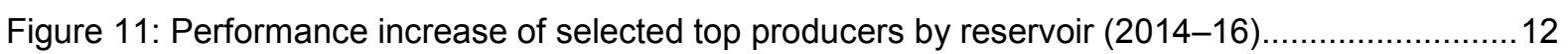



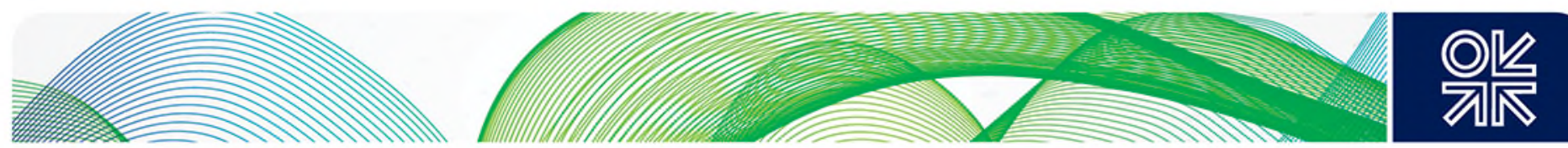

\section{Introduction}

Several US shale and tight oil plays have exhibited robust well productivity gains ${ }^{1}$ over the past two years, even as oil prices enter a third consecutive year under $\$ 60$ per barrel. The Permian, Williston (Bakken), and Powder River basins have produced the most significant gains over this period. Estimated ultimate recovery factors (EUR) ${ }^{2}$ are one measurement of well productivity. Initial 12-month oil EURs (the cumulative amount of oil a well will produce in its first 12 months) for the three plays, in aggregate, have grown by 41 per cent from 2014 to 2016, while 60-month EURs have grown by 22 per cent over that same period (see Figure 1). This begets the question, how can such strides be made in a low oil price environment in which operators and service companies alike are cutting costs, laying off employees, and reducing activity levels?

Figure 1: EUR growth in the Permian, Williston (Bakken), and Powder River basins (2014-16)

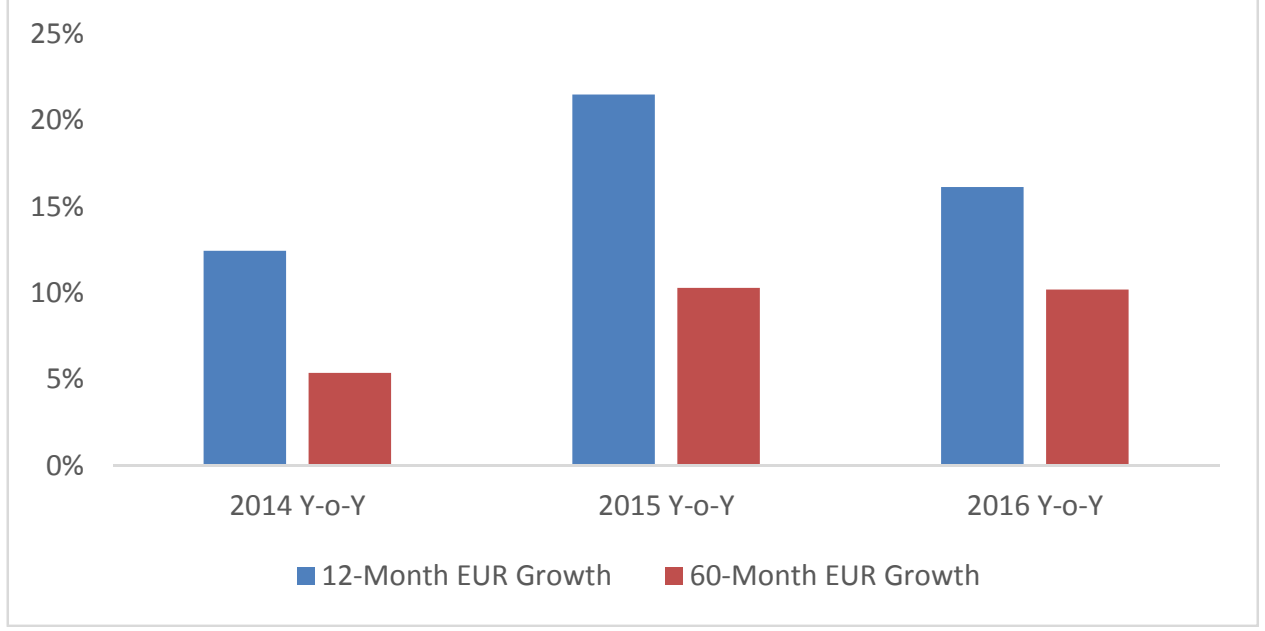

Notes: Year-on-year 12 and 60-month EUR growth rates for oil producing wells brought online in a given year in the Permain, Williston, and Powder River basins (individual well data has been combined across the three plays). Source: Drillinglnfo Data, PetroNerds Calculations and Estimates

Figure 2 illustrates the decline curve, or average well performance, for all active horizontal wells in the Permian, Williston, and Powder River basins combined, brought online in specified years. The horizontal axis shows the age of these wells in months, and the vertical axis shows the average daily oil production of these wells. Each line represents the performance of wells brought online in a given year. The orange line represents the performance of wells brought online in 2016, the light dark blue represents wells brought online in 2015, and so on. Notice how the curve shifts upward in the past three years indicating improvement in well productivity. ${ }^{3}$ Note that productivity gains are most apparent in the first two years of a well's life. After the two-year mark, performance tends to standardize across all well years (the tails overlap).

\footnotetext{
1 'Well productivity' refers to the output of a well over a given period of time. Increased output over a given period is considered to represent productivity gains.

2 'Estimated Ultimate Recovery' refers to the total amount of oil and/or gas a well is expected to produce over a given time period.

${ }^{3}$ When the curves shift upward year-on-year, this indicates that wells are producing more oil at a given age than the previous year's wells produced at that same age. As long as the curve remains above or in line with the previous year's curve, EUR factors grow as well.
} 

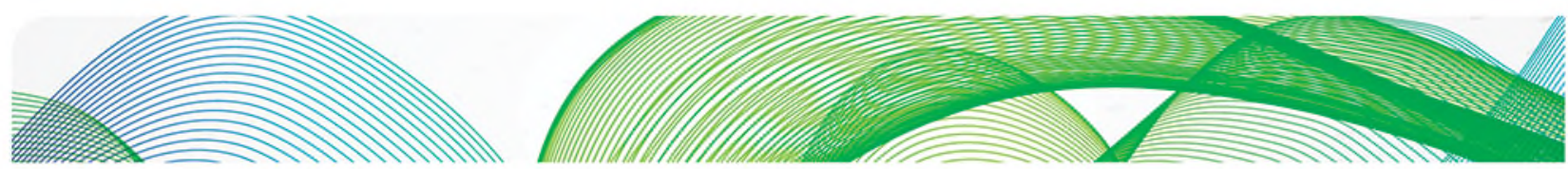
ore

Figure 2: Aggregated oil decline curve for horizontal Permian, Williston, and Powder River wells (2011-16)

600

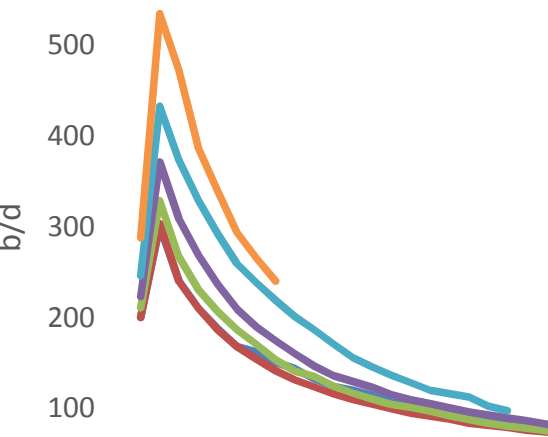

024681012141618202224262830323436384042444648505254565860626466 Months

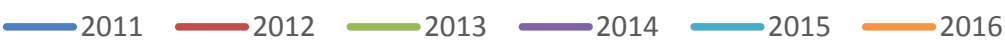

Source: PetroNerds, Drillinglnfo Data

Many US shale and tight oil producers have stated that they have become both leaner and more efficient, while also achieving technological and scientific gains that will persist when the oil market improves and, inevitably, service costs rise. However, leading oilfield service providers have stated publicly that oil producers have made few, if any, lasting technological strides or efficiency gains. Rather, they contend that producers have simply benefited from cuts in service costs (such as cost savings in drilling and completion) and that any gains or improvements will not persist when costs rise. Schlumberger stated the following in their Second Quarter, July 2016 earnings call (Seeking Alpha):

The operators have reacted to this crisis by initiating a massive reduction in oilfield activity and by sending unsustainable pricing shock throughout the entire oil industry supply chain. In addition, there is currently also a widespread high-grading of activity taking place in the industry aimed at maximizing short-term production and cash flow.

Adding up all of this, the current cost per barrel for the oil producers now appears to be significantly lower than what was the case seven quarters ago. However, this should not be confused with a permanent improvement in the underlying industry performance as there has been little to no fundamental change in technology, quality or efficiency, no major step change in industry collaboration and no general transformation of the industry business model.

... technology has to play a very important role in this. We've said in many foras that if you look at the cost per well, I think we are in late innings, but in terms of production per well, we are in very early innings. And if you want to drive down cost per barrel, we have to look at ways of getting more production out of each well. But - although utilization will help ... given the pain that the entire industry value chain is in, there's going to be a mounting wave of cost inflation from every supplier in that chain, which I think is going to put significant pressure on how quickly activity can recover. 

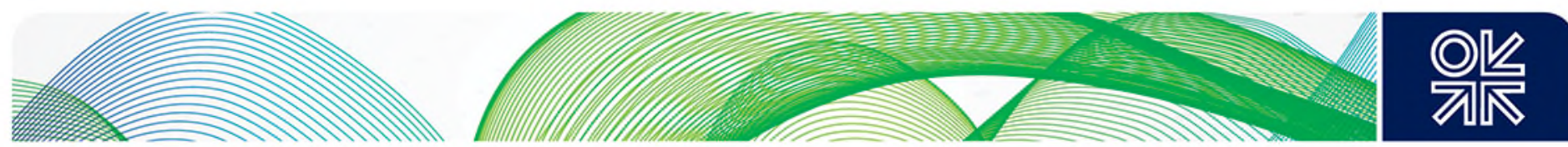

While Schlumberger's tone has moderated in their most recent earnings call, their words in July serve as a harsh rebuttal to conflicting statements from a number of operators. Oasis Petroleum discussed several Bakken-related developments that are leading to increased oil recovery - specifically completion design changes - in their Second Quarter, August 2016, earnings call (Seeking Alpha):

Equally important to cycle times are job design and implementation. Last quarter, we spoke about many of the completion designs that we are testing this year. These tests fall into two camps: higher proppant loadings and proppant placement efficiency. ${ }^{4}$ For high-proppant loads, we have completed multiple 10 million pound and 20 million pound fracs in Indian Hills and Wild Basin. For proppant placement, we have completed several 50-stage slickwater jobs and have also tested both diverters and precision proppant placement techniques ... it's simply too early to draw definitive conclusions. However...we believe these designs and techniques have the potential to further enhance both EURs and returns for Oasis.

In their Second Quarter, August 2015 call, EOG discussed the customization of well completion designs and the resulting effects on decline rates, and the uplift in well productivity (Seeking Alpha):

... we continue to drill our laterals in better rock ... we are taking a lot of time and effort, picking out the best quality rock in each one of these plays and keeping the lateral in that longer ... we now are doing a much better job with these high density fracs and better distributing the frac along the lateral, connecting up more of that good rock. ${ }^{5}$ And it [is] certainly lowering our decline rates over time and that makes it easier to grow production... No two wells are exactly the same. We always customize the completion job based on the geology.... But, we are seeing a tremendous uplift in the productivity of the wells.

Source: All earnings call quotes via SeekingAlpha.com

Notable here is that EOG mentions the major step changes taking place in completions design. These changes include deeper assessment of rock quality, the importance of keeping the well lateral in higher quality rock or reservoir, and also optimizing the placement fracks along the lateral, as opposed to the common practice of placing frack stages at pre-defined, standard intervals. These and many of the other completion changes will be explained throughout the course of this paper.

This paper seeks to assess the level of well productivity changes and well production improvements in the US shale and tight oil space since the collapse of oil prices in 2014. This paper also seeks to analyse the nature of these productivity changes through an assessment of the role of cost cuts, efficiency gains, and technology advances on the performance of recently developed shale and tight oil wells. This assessment is performed through the analysis of individual well data and research into company behaviour through earning calls, press releases, and meetings with key shale companies.

\footnotetext{
4 'Higher proppant loading' refers to the addition of large volumes of proppant (such as sand) as part of the hydraulic fracturing process. Proppant volumes vary by basin (and even within basins) and by operator over the course of the oil price downturn. However, the amount of sand loadings per lateral foot of wellbore has continued to steadily rise across all basins. 'Proppant placement efficiency' refers to the more precise placement of proppant, typically sand, downhole. This also refers to the treatment of the well through the completion process and improved placement of the fractures during completion to better connect the rock and increase production.

${ }^{5}$ The term 'high density fracs' here is a specific reference to EOG's statement regarding their fracturing treatment method - a method that primarily utilizes more sand and more frack stages. 'Frac distribution' refers to the actual distribution of the fracture stages along the wellbore and the placement of those perforation clusters.
} 

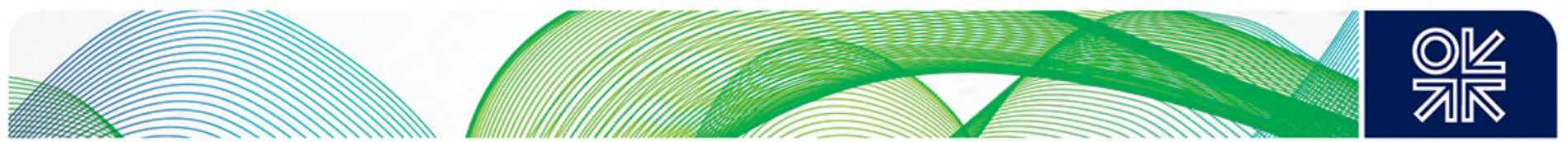

\section{The productivity gains}

Several US shale and tight oil plays have benefited from significant oil well productivity gains since the downturn began in 2014. The focus of this paper is on productivity gains in the Permian, Williston, and Powder River basins, although several other basins and plays, including the Anadarko basin and the Eagle Ford's oil window, have also seen productivity increases.

Figure 3 and Figure 4 show oil production and new horizontal and vertical well additions, for wells that remain active, in the Permian, Williston, and Powder River basins, and the Eagle Ford reservoir. Permian basin production has grown throughout the downturn, even with a sharply declining rate of well additions. (Vertical well production has declined considerably in the Permian, but strong growth in horizontal well production has more than offset these declines.) Eagle Ford production has declined markedly since the spring of 2015 given reduced activity levels and the varying product windows: oil, volatile oil, condensate, and gas production in the reservoir. Williston basin production has also continued to decline, as many producers have allocated available capital to other plays. Powder River basin production has declined, but it appears to be holding steady at current levels due to increased completion activity undertaken by larger producers.

Figure 3: Oil production in four plays (2013-16)

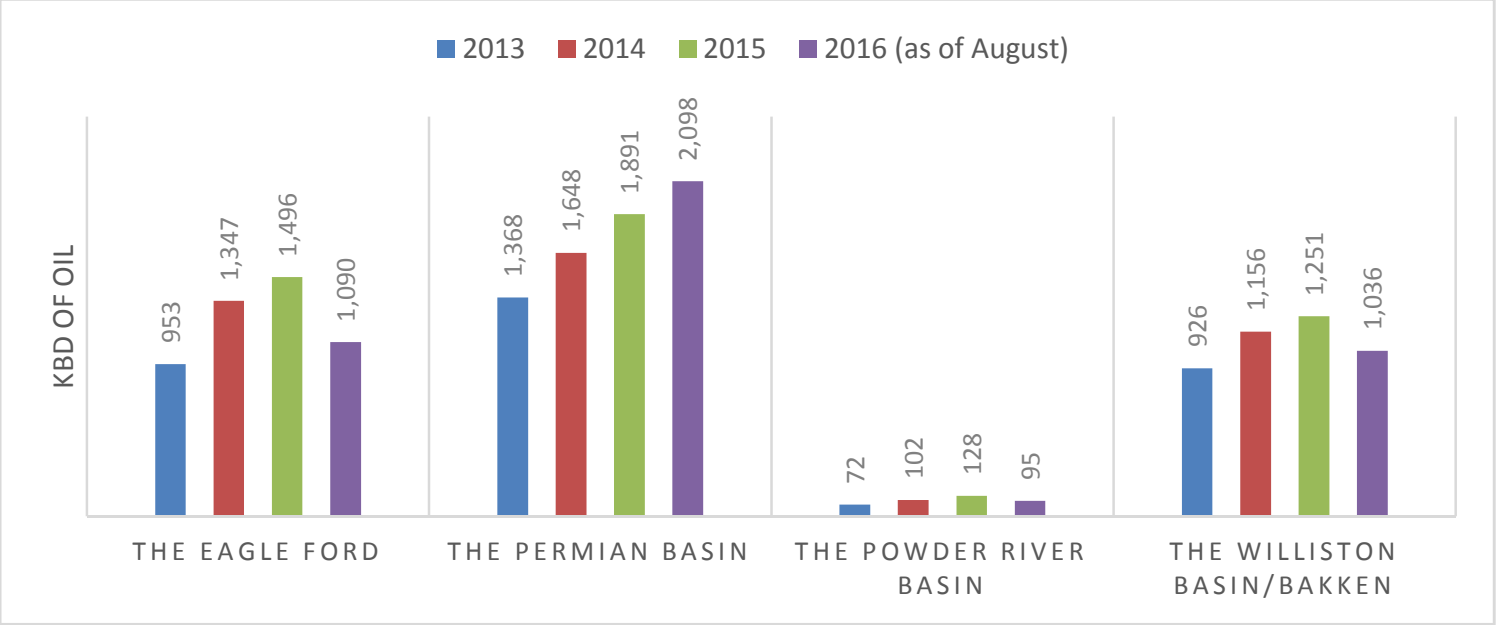

Source: DrillingInfo Data, PetroNerds

Figure 4: Well additions in four plays, horizontal and vertical (2013-16)

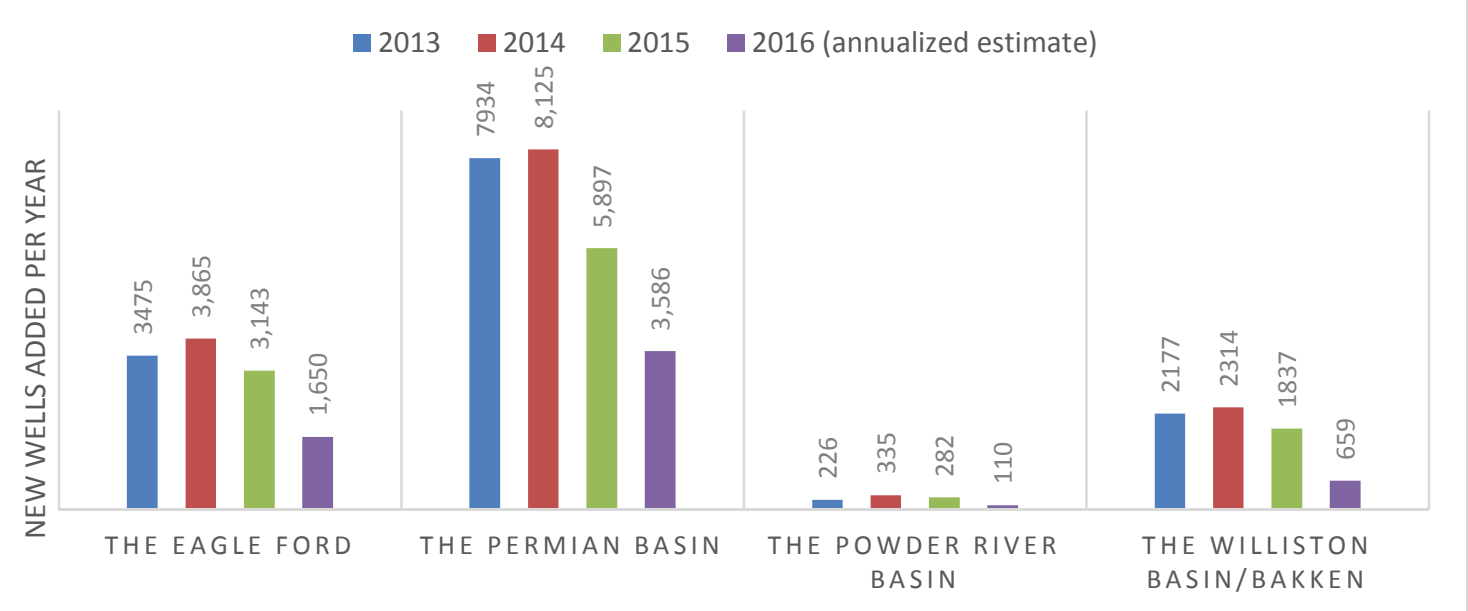

Source: DrillingInfo Data, PetroNerds 

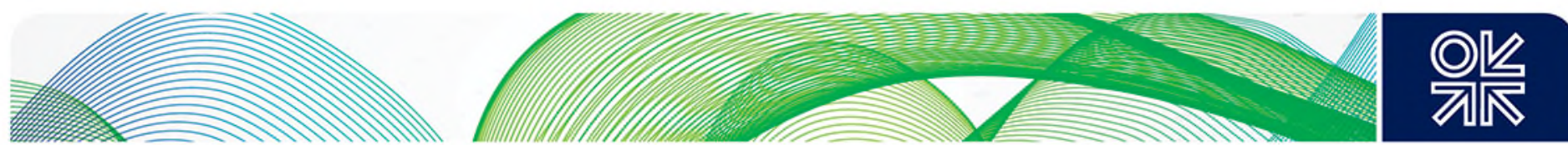

\section{The Permian}

The Permian basin, which spans from across West Texas into south-eastern New Mexico, has been a prominent conventional US oil play for nearly a century. But in the past several years, shale oil production techniques - such as horizontal drilling and hydraulic fracturing - have been applied at scale to numerous reservoirs in the Permian basin, morphing it into a hybrid conventional/unconventional tight oil play and reversing the basin's downward production trajectory. Remarkably, Permian basin oil production has grown by a third (500,000 b/d) since the start of 2014 . The Permian basin is the 'hottest' play at the moment. In 2016 there have been a large number of acreage sales, acquisitions, and discovery announcements while acreage prices have skyrocketed, all in the midst of sub- $\$ 60$ oil prices.

Growth has, in large part, been spurred by the application of unconventional drilling technologies (which are becoming more conventional by the day) in reservoirs that had previously been treated as conventional formations - such as the Bone Spring, the Trend Area, and the Wolfcamp reservoirs. Figure 5 shows annual type curves for horizontal wells added since 2011. Note the sharp upward shift of the curves that began in 2014 - the start of the oil price collapse - as the broad application of unconventional oil production techniques became widespread. Initial production (IP) rates rose from less than $300 \mathrm{~b} / \mathrm{d}$ for 2013 wells to over $500 \mathrm{~b} / \mathrm{d}$ for 2016 wells, while tails for the first 36 months of a well's life are holding above the tails of wells from 2013 and earlier.

Figure 5: Permian basin type curves (2011-16)

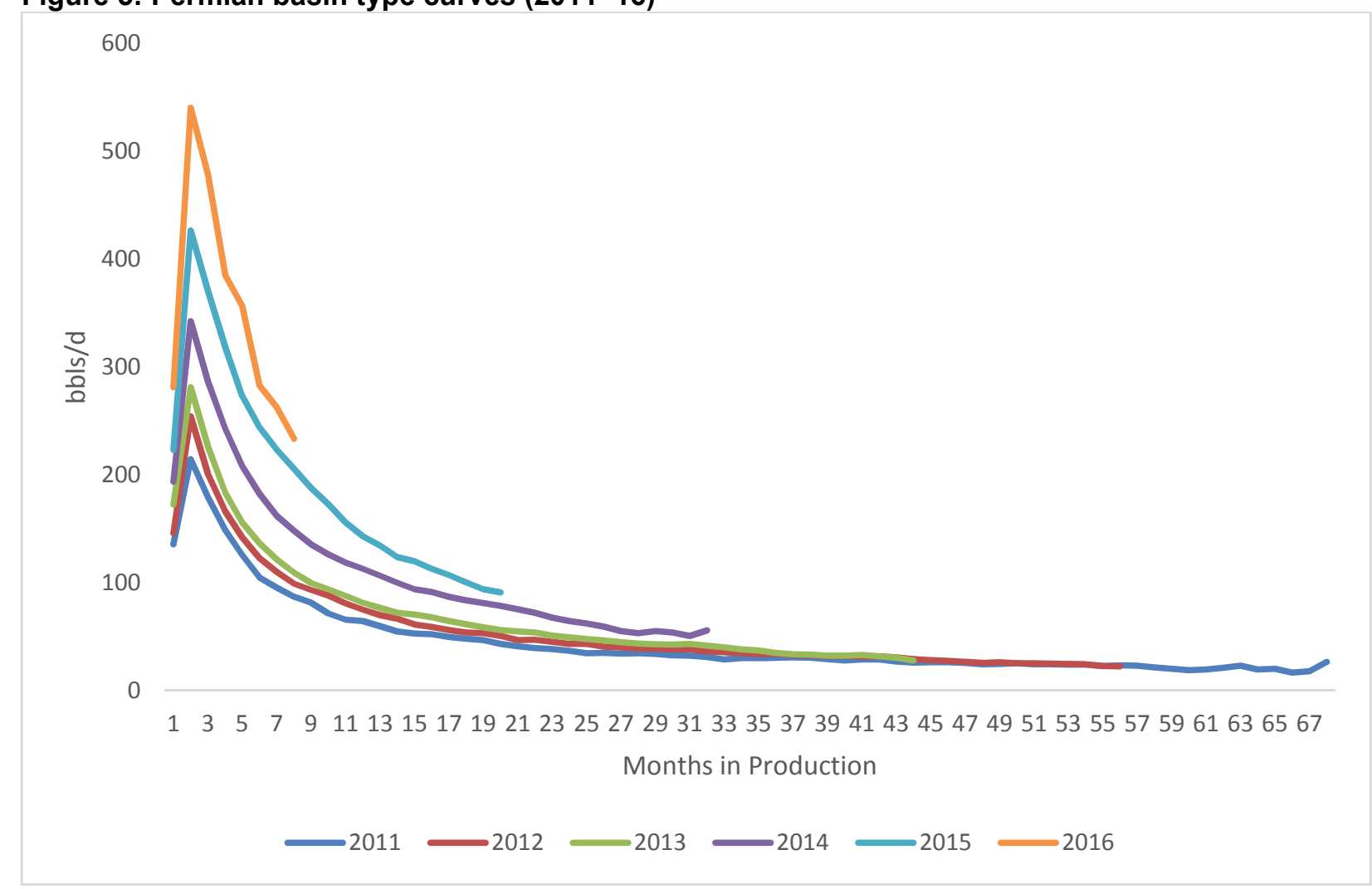

Source: DrillingInfo Data. Horizontal wells only

The Permian basin has received a great deal of attention and hype of late and has attracted larger amounts of drilling and completion activity, relative to the other oil plays, during the ongoing downturn. For each of the past three years, more wells have been added in the Permian basin than in the Williston basin, Powder River basin, and Eagle Ford combined. 

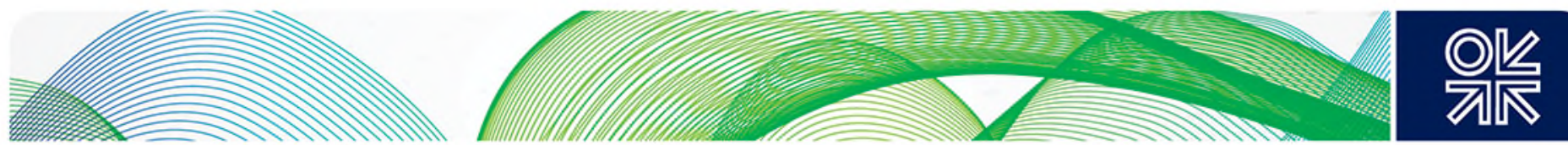

There are several reasons for the Permian basin's rejuvenation. The Permian basin is one of the USA's largest and oldest producing basins. It is a well-known, well-delineated oil play with over 156,000 active wells. Throughout the shale and tight oil boom, producers have been active in the Permian basin, but many of them were predominately drilling and producing vertical wells until very recently. In 2015 , nearly 3,000 vertical wells were brought onto production. ${ }^{6}$ Only in the past few years has horizontal drilling spread widely across the basin.

Figure 6 identifies vertical and horizontal well production in the Permian basin separately. Notice the sharp increase in horizontal production and the relatively small well count, in comparison to the vertical well count. In November 2014, when oil prices were just beginning to correct, horizontal oil production in the Permian basin was just over $750,000 \mathrm{~b} / \mathrm{d}$, far below that of the Bakken and Eagle Ford. Horizontal oil production has now climbed to over $1.2 \mathrm{mb} / \mathrm{d}$.

\section{Figure 6: Permian basin vertical and horizontal well oil production (2000-16)}

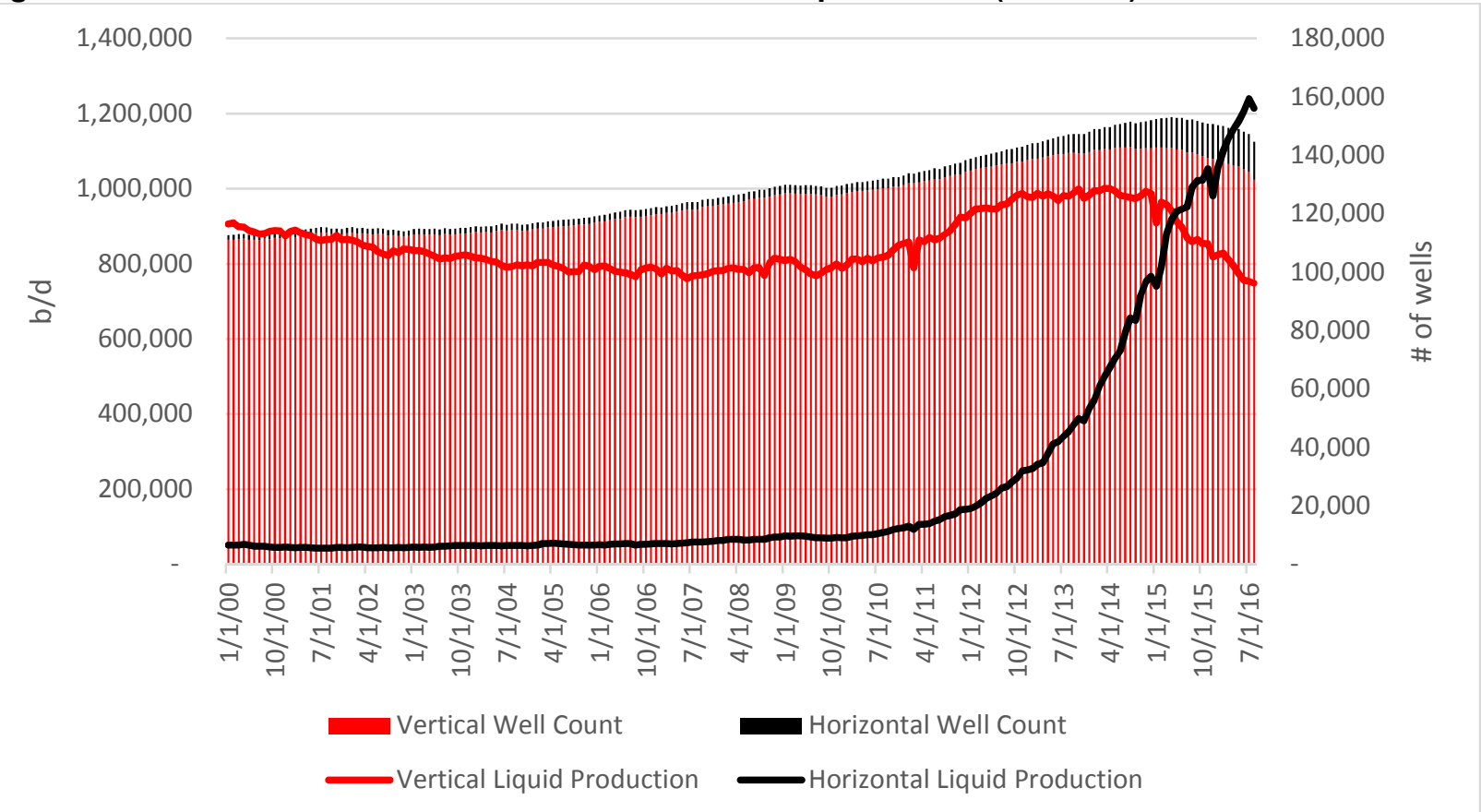

Source: PetroNerds, DrillingInfo Data

Because the Permian basin is a more recent entrant into the shale/tight oil space (with respect to the application of horizontal drilling and fracturing) many operators have only recently begun to hold a majority of their acreage by production. ${ }^{7}$ Since 2014 , operators have been drilling and completing wells to bring them onto production, not only to prove up acreage positions, but also to maintain control of their existing leases. Hundreds of operators participate in the Permian basin and production is not nearly as concentrated amongst the top producers in the Permian as it is on other plays, such as the Williston basin and Eagle Ford. Many Permian producers needed to continue drilling and producing in order to hold their acreage by production and fulfil their leasing requirements. As oil

\footnotetext{
${ }^{6}$ At least some of the vertical wells brought onto production in 2015 were added to hold acreage by production or have resulted from a number of other factors and circumstances related to individual operators - including acreage sizes (limitations) and leases, as well as capital restrictions.

${ }^{7}$ When acreage is held by production, it means that an operator is not compelled to bring additional wells onto production in order to maintain their existing lease. Because many operators have been drilling and completing wells in the Bakken since 2008 (and before), the majority of Bakken producers had their acreage almost fully held by production when oil prices began to correct. Larger operators (such as EOG Resources and Continental Resources) began shifting their capital to areas which required new production in order to hold leases, as well as additional asset delineation to increase reserves, as this is important for borrowing base redeterminations.
} 

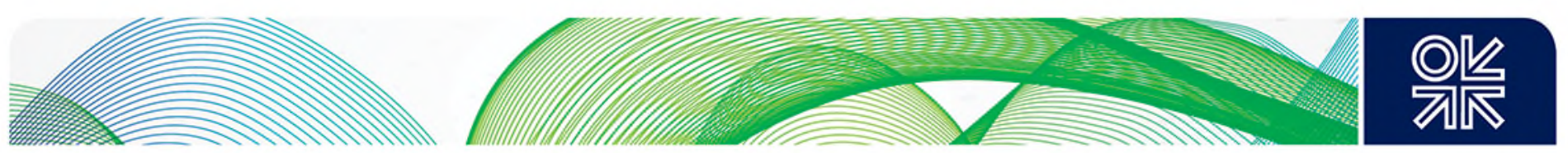

prices began to decline, many operators were just beginning to aggressively delineate the many stacked reservoirs in their acreage. This is evidenced by the increase in reserves, announced quarterly, for many operators, and the longer laterals being drilled by these producers. The confluence of the need to hold acreage by production, and the long-term financial benefits of proving up acreage and delineating assets, has driven a large amount of activity throughout 2015 and 2016.

\section{The Bakken}

The Bakken is perhaps the most mature unconventional tight oil play in the USA. The 'maturity' of a shale plays refers to the amount of time during which producers have been drilling and producing from it using unconventional techniques such as horizontal drilling and hydraulic fracturing. The Bakken began its boom in the early 2000s and the Eagle Ford came online around 2010. The Bakken, perhaps counterintuitively, has not seen the same degree of advanced fracturing and stimulation activity as the Permian basin. Many of the methodological and technological gains made over the course of the recent downturn have been disproportionally applied to the less mature plays, such as the Permian. By 2014, most Bakken acreage was held by production, and Bakken operators were just beginning to get their teeth in the Permian basin when oil prices began to come down in late 2014. This greatly reduced the flow of capital to the Bakken, as operators were not pressed to drill new wells there because their acreage was held by production, and because a rush began to delineate the unconventional portion of the Permian. Despite reduced activity since 2014, the current productivity gains taking place in the Bakken indicate that there is a lot of running room left to improve well performance in the Bakken.

The Bakken, Eagle Ford, and Powder River have seen far less drilling and completion activity than the Permian basin. The top ten producers in each of the former plays control two-thirds or more of production, whereas in the Permian the top ten producers control approximately half. Because the first three plays listed above are more mature, in the unconventional sense, the majority of companies active in them have their acreage fully held by production. Recent activity in the Bakken has largely been generated by companies whose sole asset, or major shale asset, is in the Bakken. However, several of the majors, who were late participants in the shale story compared to many US independent oil operators, are actively drilling and completing wells in the Bakken and other shale oil plays, in order to learn, delineate assets, and book reserves. When oil prices improve, the Bakken should benefit from the operators who have made advances in well completions in other plays.

Although the Williston basin is among the most mature of all US unconventional oil plays, its largest year-on-year productivity increases occurred in 2015 and 2016, the first two full years of the current oil market slump. While it may be mature relative to other unconventional plays, their rise over the past decade or so represents little more than a blip in the timeline of the oil era. Operators are still learning much about the Williston basin and its Bakken and Three Forks reservoirs. The downturn has been important to the learning process, as this paper will discuss.

Figure 7 shows the type curve for the Williston basin. Annual productivity improvements in the Williston basin have been less dramatic than in many other unconventional plays. But 2015 and 2016 have ushered in the Williston's largest productivity gains since before 2011. It is interesting that the most mature unconventional oil play is just now showing its largest productivity improvements in many years. 

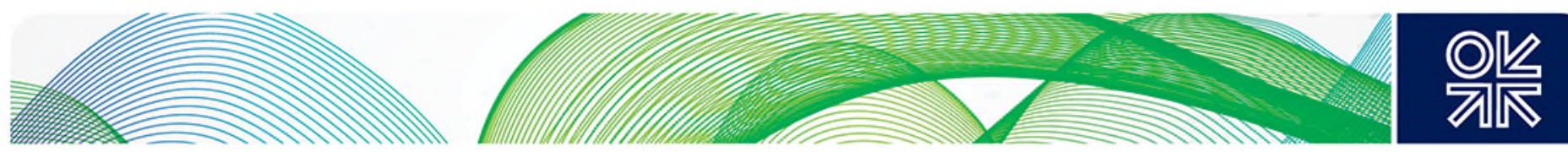

Figure 7: Williston basin type curves (2011-16)

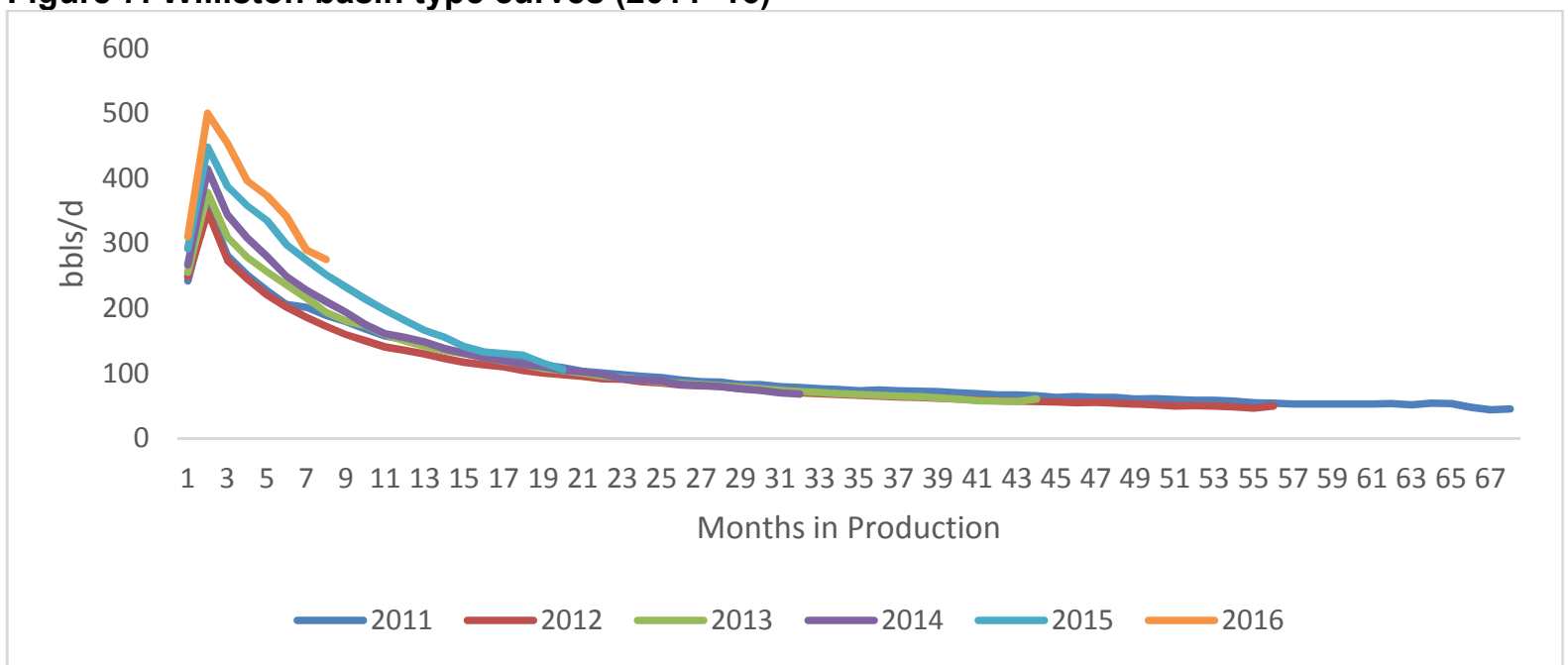

Source: Drillinglnfo data. Horizontal wells only

Note how the tails of all Williston basin wells fall in line after about 20 months in production, regardless of how strong earlier production has been. Several operators in various plays are examining ways to flatten the decline curve, thus lifting EURs. EOG, in their Q1 2015 earnings call, described the relationship between their integrated completion design and decline rates (Seeking Alpha):

On these integrated completion, it's not a whole lot of different than what we've always been. We've always focused on the very best rock and the very best interval within the overall section. And we try to keep our lateral in that and then when it comes with completions, we integrate that in as well. And we do very; we basically design each stage for the well and for that specific portion of the lateral.

What we're seeing on our new completion approach is by targeting the wells in the better pay zones and then doing a better job of placing the completions along the lateral is we're seeing actually that declines are flattening over time.

Focus is beginning to shift away from simply increasing IP rates (which have long been a simplistic measurement used to market or promote assets) and short-term productivity to lifting overall well performance across the curve and increasing EURs.

\section{The Powder River basin}

The once-conventional Powder River basin in Wyoming was just beginning to come alive as oil prices fell in 2014. It currently produces under 100,000 b/d but has seen extraordinary productivity gains with the recent application of unconventional oil technologies, but as Figure 8 indicates, 2016 wells have reversed course after a breakout in 2015. The sample size of 2016 wells, however, is quite small compared to other plays (less than 100 wells thus far) and the bulk of production is controlled by just a few producers.

The Powder River is expected to re-emerge as a popular play during an oil market recovery. Several larger operators - such as Devon, Chesapeake, and even majors such ConocoPhillips - are active in the oil play and they have held onto their assets during the downturn. EOG has added to its Powder River position through its acquisition of Yates Petroleum, which also has assets in the Permian. The combination of strong productivity gains, the presence of well-capitalized companies, solid midstream infrastructure, and Wyoming's history as a stable oil production environment bodes well for the Powder River's future. 

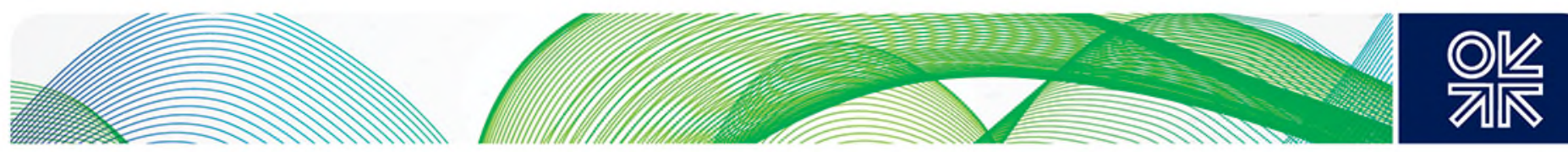

Figure 8: Powder River basin type curves (2011-16)

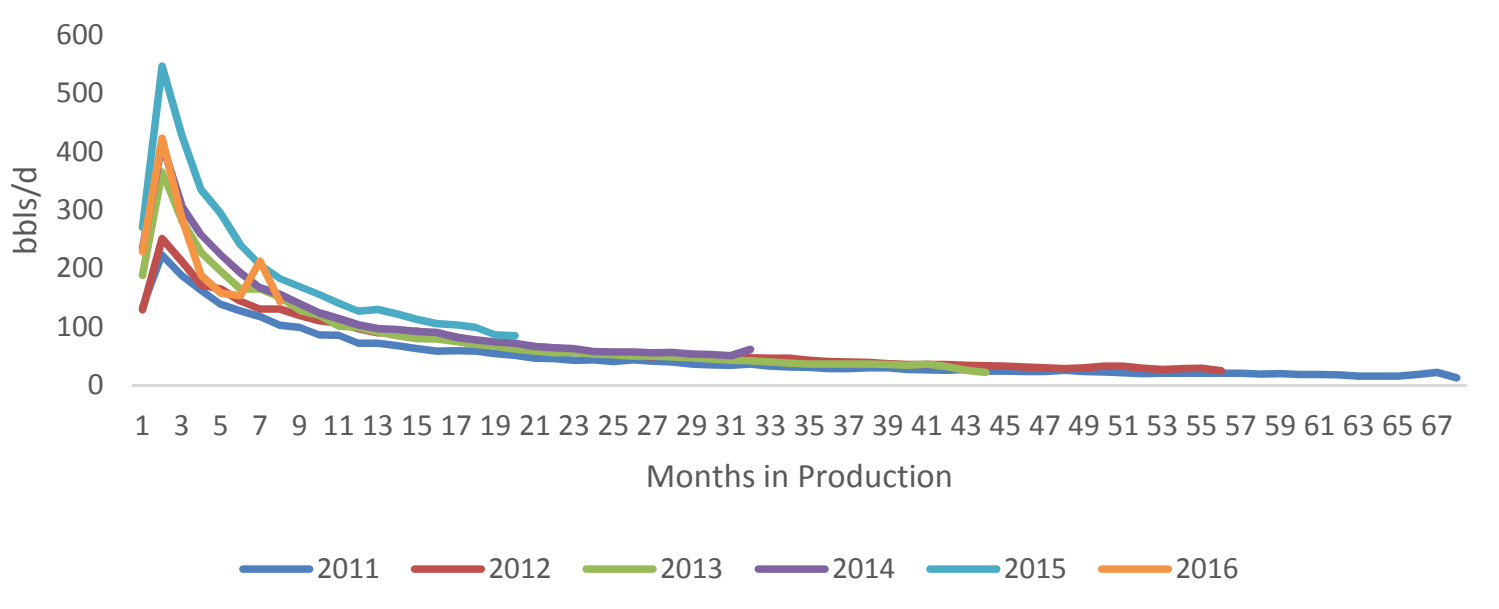

Source: Drillinglnfo data. Horizontal wells only

\section{The Eagle Ford}

The Eagle Ford has experienced the most severe production declines since 2014, and during this period well productivity has not improved for most operators. The Eagle Ford is not strictly a tight oil play and is in many aspects far different from its peers. Production in the Eagle Ford is largely controlled by the top ten producers operating there, and many of these producers have the majority of their acreage held by production. Additionally, most of these producers have assets in the condensate and volatile oil window, as opposed to the crude oil window, in which increasing well productivity is not as straightforward. EOG Resources has continued to drill, complete, and bring wells onto production aggressively during this oil price downturn, and that company controls most of the acreage in the crude oil window. EOG has generated strong productivity increases in its wells.

Figure 9 indicates the decline/type curve for the Eagle Ford reservoir. Notice how the IPs have increased somewhat year-on-year, but the curves have not shifted upward and outward as seen in the Bakken and Permian. By comparison, Figure 10 shows EOG's type curve in the Eagle Ford, and this shows sharp improvement.

\section{Figure 9: Eagle Ford reservoir type curves (2011-16)}

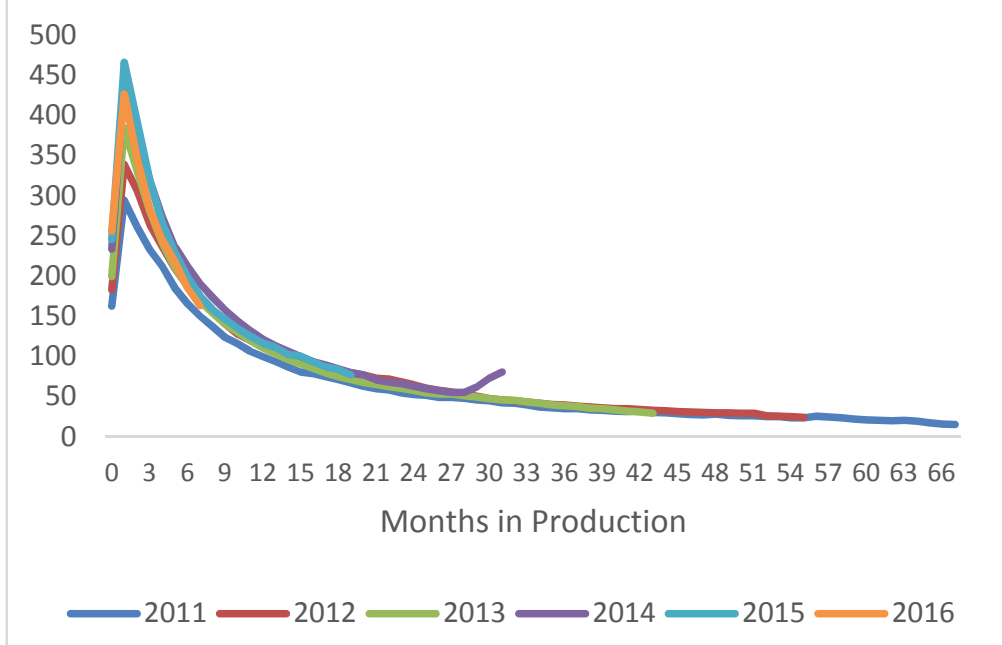

Source: Drillinglnfo data. Horizontal wells only 

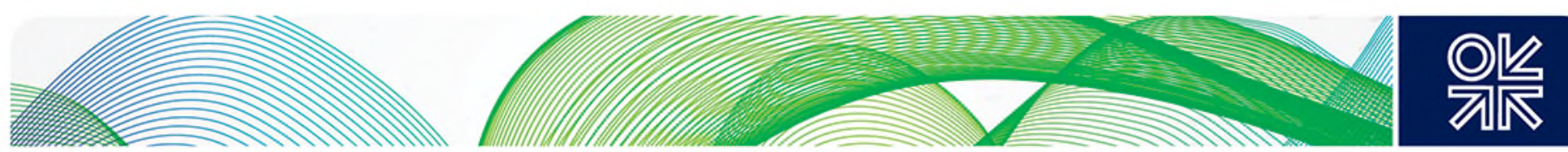

Figure 10: EOG Resources, Eagle Ford reservoir type curve (2011-16)

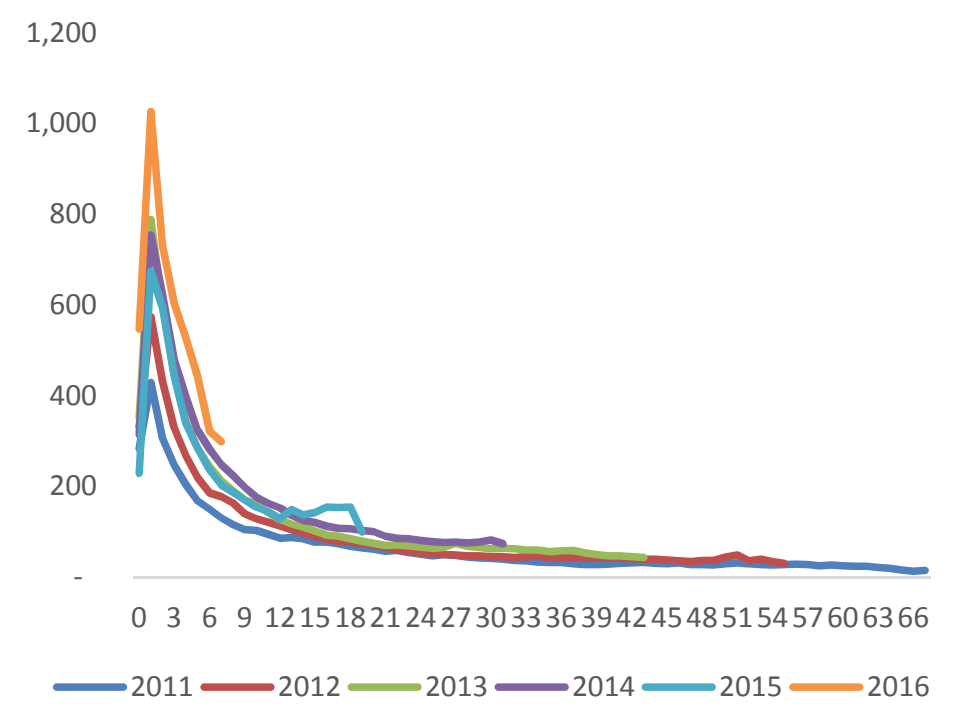

Source: DrillingInfo data. Horizontal wells only

\section{The factors behind productivity gains}

\section{Addition by subtraction}

Before discussion of all the activities that operators and producers are currently undertaking to increase well productivity, it is also important to discuss how high grading and the absence of lower performing operators are affecting the appearance of productivity gains. The fact that a number of smaller producers - many of which are cash-strapped, with a history of below average well performance - have either reduced their rate of well additions or halted new completions entirely is an important factor in the upward shifts of the type curves provided in the previous section. The disappearance of such producers and their wells has effectively caused the 2015 and 2016 decline curves to shift upwards independently of any productivity gains among producing wells.

In each play, fewer companies added wells in 2015 than in 2014 and fewer still in 2016 than 2015. The downturn has generally caused small and/or cash strapped operators to respond in one of two ways:

- some companies have continued to add new wells at a strong pace to generate much needed cashflow even if economics are less than ideal,

- others have hunkered down and scaled back drilling and completions activity, in certain cases to nothing, in order to preserve cash and wait for prices to recover.

The latter strategy has reduced the pool of companies adding new wells. And because such companies have often, but not always, brought online wells of a lower calibre in past years, (perhaps due to poorer acreage positions or a lack of capital to invest in science or completions), their absence provides a boost to the productivity curves.

A second and somewhat related contributing factor is high grading. New well additions have declined year-on-year since 2014 in each of the three basins covered in this paper. But drilling and completion activity reductions are not distributed evenly across each play. First of all, there has been a reduction in drilling activity in non-core areas of each play (the areas of a play known to be less productive). Given that drilling and completion costs are relatively consistent within a play, in a low oil price 

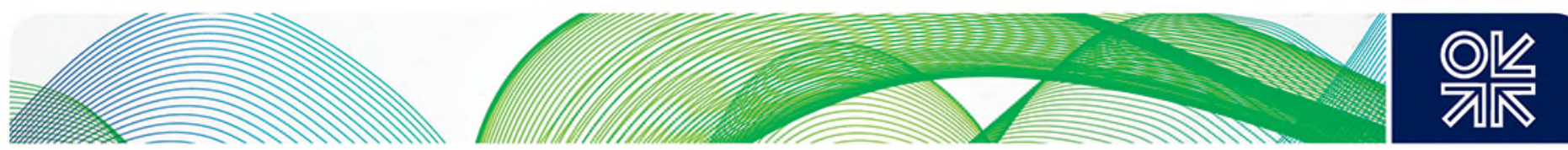

environment a well of lacklustre productivity might struggle to generate an economic return when compared to a high productivity well drilled and completed at the same cost. Therefore, many companies tend to 'high grade', or produce only their highest-grade geology. This lends the appearance of productivity gains in type curve charts when the true cause is that poorer performing geology is being held back until economics improve.

\section{Productivity gains not a fluke}

The culling of low-performance geology and companies is an important factor in this discussion, but ultimately it does not explain the entirety of productivity gains. A review of company-level well performance over time for a number of reservoirs in the Permian, Williston, and Powder River basins shows that a large number of companies have increased well productivity from within their existing acreage positions across a variety of reservoirs since 2014 . This indicates that productivity gains are being made within individual acreage positions, that this effect carries over to many reservoirs (rather than just migrating to a new reservoir/layer from within a single acreage position), and that gains are attributable to far more than high grading and the absence of lower-performing companies.

Figure 11 shows company-wide well performance productivity from 2014 through mid-2016 in aggregate for three of the top operators in selected reservoirs. It illustrates the year-on-year productivity increases in individual reservoirs, as exhibited solely by the selected operators in those reservoirs. ${ }^{8}$ The performance bars in the chart are indexed to each reservoir's average 2014 horizontal well (which equals one). Therefore, a value of 1.5 in the Bone Spring reservoir of the Permian basin means that the average well productivity for all wells brought online in a given year for the three selected operators was 1.5 times that of the average 2014 horizontal Permian basin well. The productivity of each and every well is adjusted for age against that of the base well.

The results indicate that when data is limited to individual companies within individual reservoirs and acreage positions - thus eliminating the productivity effect created by the absence of lower performing operators and reducing the influence of high grading, when operators move from less productive reservoirs to more productive reservoirs - performance gains are robust.

Well productivity among the selected operators doubles or better in each of the assessed Permian basin reservoirs, even as oil prices declined during this time period. Because the Permian basin had largely been a conventional, vertical well-driven play prior to 2014, it starts with a relatively low baseline. However, the application of unconventional tight oil technologies and increasing lateral lengths has rapidly transformed the Permian basin into a premier tight oil play that benefits from being adjacent to robust midstream infrastructure and a world-class refining hub, hence the attention it has received in 2016.

\footnotetext{
${ }^{8}$ The companies selected in this chart are among each reservoir's most productive on a per-well basis (not necessarily the top three) and have added a significant number of wells in each year. The companies, listed beneath the chart, have been selected to strike a balance between demonstrating well productivity growth while also allowing for an adequate sample size of wells.
} 

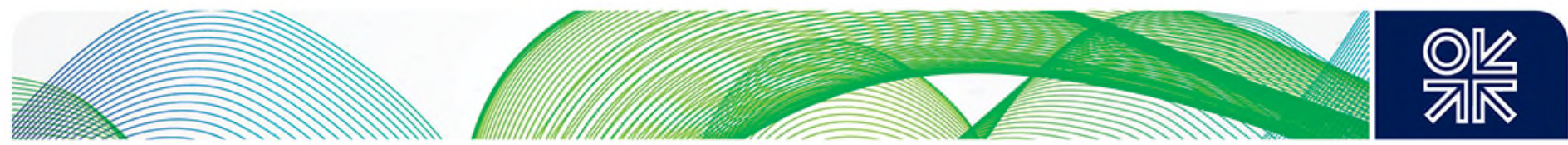

Figure 11: Performance increase of selected top producers by reservoir (2014-16)

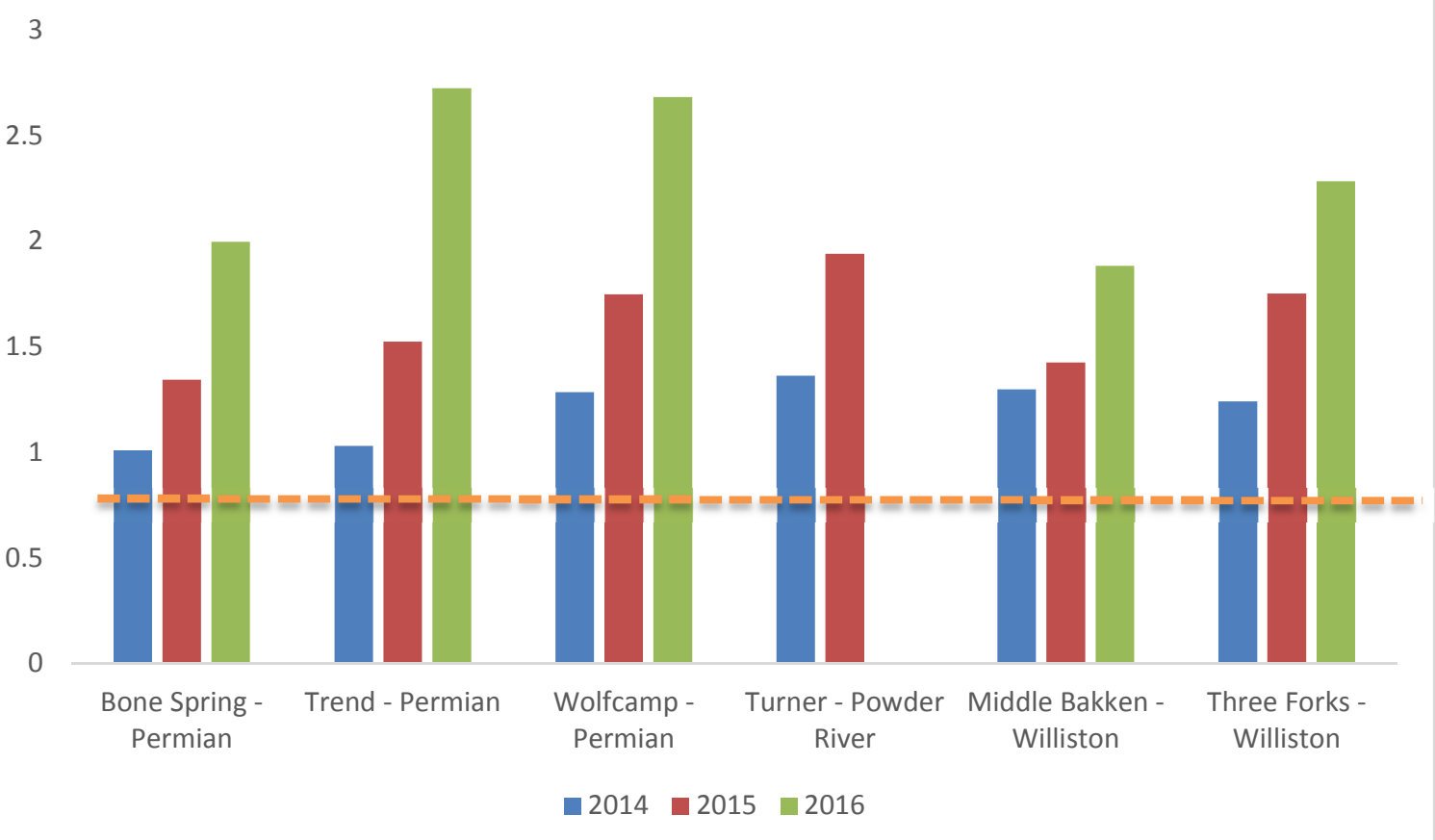

Source: PetroNerds, Drillinglnfo data.

Bone Spring operators: Concho Resources, EOG Resources, Mewbourne Oil Company;

Trend operators: Concho Resources, Encana, Pioneer Oil Company;

Wolfcamp operators: Cimarex Energy, Concho Resources, EOG Resources;

Turner operators: Ballard Petroleum, EOG Resources, Peak Exploration and Production;

Middle Bakken operators: EOG Resources, ExxonMobil, Whiting;

Three Forks operators: ConocoPhillips, Oasis Petroleum, QEP Resources

Productivity grew by approximately one third in the Powder River's Turner reservoir during 20142016. The Turner, along with the rest of the Powder River basin, is also new to horizontal drilling and other unconventional technologies, but has been a productive conventional reservoir for decades. (The sample size of 2016 wells was too small to include in the above chart.) The Turner is the most prolific in the highly concentrated Powder River basin, where only two companies produce over $10,000 \mathrm{~b} / \mathrm{d}$. A small batch of companies is responsible for the bulk of the performance increases and these increases will likely garner more attention and activity in the future, if and when the oil market recovers.

The two major reservoirs of the Williston basin - the Middle Bakken and the Three Forks beneath it have exhibited strong productivity gains despite a number of headwinds and the fact that typical lateral lengths have remained stuck at precisely $8,000 \mathrm{ft}$. for several years running (lateral lengths have been increasing in the Permian and Powder River basins). Transportation (midstream) constraints have lowered wellhead values and have had a more detrimental impact on activity in the Williston basin than in most other plays. A very small of independents have added wells in 2016, in part due to economics and the relatively high drilling and completion costs in the Williston. The Williston basin and Bakken tends to be driven by medium-sized independents and larger, whereas in the Permian and Powder River basins (both older plays), small independents play a more integral role. 

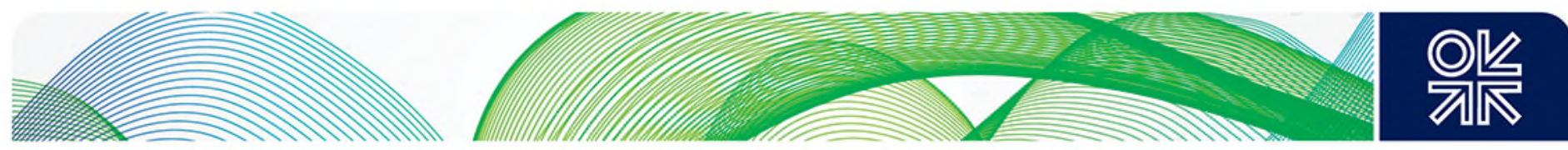

\section{How lower costs have enabled productivity gains}

At the beginning of the downturn, companies often discussed high grading and high intensity completions - essentially the act of drilling one's best acreage and pumping a lot of proppant (typically sand because it is cheaper) down the well. For many of these companies, high grading increased both IPs (initial production rates) and much needed cashflow in the near term. Now, operators are beating the same drum about efficiency gains, well productivity increases, and cost reductions. Several large independent producers - such as Pioneer Resources, Continental Resources, and Oasis Petroleum - have all, in 2016, turned free cashflow positive on a quarterly basis, after being free cashflow negative on an annual basis since at least 2013.

Emphasis is frequently placed on cost concessions from service providers, together with efficiency gains via quicker drilling times, better completion designs, precision lateral placement, more accurate fracture treatment, and reduced decline rates. In general, operators tend to attribute half the cost savings to service providers and vendor price cuts and roughly half to internal efficiency gains and operational improvements. They believe, or at least state on their earnings calls, that many of these efficiency gains will stick even when oil prices increase and the cost of services goes up. Many operators have announced a roughly 25 per cent to 45 per cent drop in drilling and completion costs across basins. For example, wells that cost $\$ 9$ million to drill and complete in the Bakken in 2014 now cost roughly $\$ 5$ million for some operators.

Oilfield service providers - those often completing the wells and doing frack jobs for operators - have cut prices dramatically throughout this downturn, to keep clients and maintain market share. These service providers have actively reduced the costs of their services and supplies but some operators have repeatedly missed payments to these service companies. Wages have been reduced, tens of thousands of people have lost their jobs, and over 100 service companies have gone bankrupt since January 2015 in North America alone. ${ }^{9}$ Input costs from other vendors (including equipment and infrastructure such as tank batteries, pump jacks, frack sand, and tools) have dropped. These price cuts have been dramatic in categories like pressure pumping (the horsepower required to pump sand and fluids down a well during fracturing treatment) and equipment and rental costs, but also quite significant in drilling and wireline services.

\section{Doing more with less}

Lower costs have allowed producers not only to continue to drill and produce new wells, but also to engage in research-oriented activities with long-term benefits. This included taking the time to review and study assets and reservoirs and to dedicate capital to G\&G (Geological and Geophysical) investments. Operators are gaining a greater understanding of the geology and rock quality while also making use of more efficient rigs, geo-steering technology, longer laterals, and increased horsepower and pumping pressure. The better capitalized companies have more freedom to spend on research, and it is possible that those operators who have invested in research during the downturn will emerge from it well ahead of the curve.

Reductions in drilling and completion times are among the most straightforward efficiency gains to be made during the downturn and represent a continuation of a downward trend in drilling times over the past several years. Shorter drilling and completion times mean that operators pay less in rig, service, and equipment costs. It is important to note that despite shorter drilling times (which could in theory be detrimental to lateral placement and well performance if not done properly) well productivity has

${ }^{9}$ According to Haynes and Boone, 25 October 2016. 

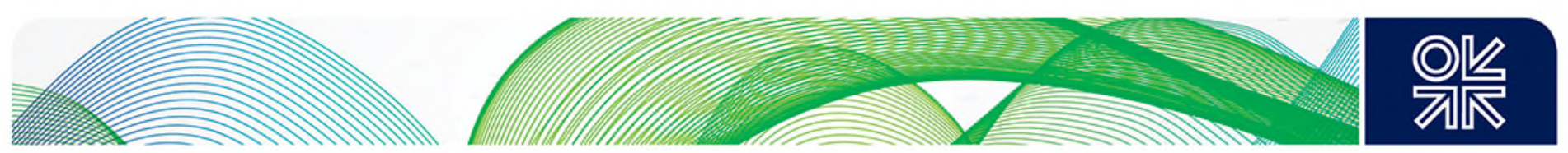

improved for many of the very operators who are speeding up drilling and completion times, even as lateral lengths tend to increase.

The overall slowdown in activity levels, in conjunction with faster drilling and completion times, is proving beneficial to operator efficiency. Although many operators tout the fact that they are drilling a well from spud to Total Depth in a matter of days, the processes both before and after drilling have slowed down greatly; this has allowed operators to better examine data in order to more accurately drill, land in zone, frack, and treat, and ultimately to achieve greater well productivity.

The height of the boom in 2014 could be described as managed chaos. Oil prices were over $\$ 100$ per barrel and companies were drilling and completing wells as quickly as possible to capitalize on high prices. Now, at half that price, operators are drilling and completing individual wells quickly, but overall drilling programmes are moving at a much more manageable pace. At $\$ 50$ per barrel, operators must be thoughtful and efficient if they are to generate positive cashflow from operations.

\section{Taking advantage of low costs}

Costs are beginning to rise across the service sector ${ }^{10}$ but increases might not initially be fully absorbed by operators. Operators have utilized this low-cost environment to drill wells and add infrastructure that will be employed when prices pick up. These operators were utilizing contracted rigs $^{11}$ and taking advantage of the low-cost environment to make investments while prices were low. The industry now has an inventory of thousands of drilled but uncompleted wells (DUCs). These wells await completion and will be brought online as oil prices rise. Likewise, companies have installed much of the necessary infrastructure on these DUCs. This infrastructure placement includes onsite equipment and facility costs such as pump jacks and tank batteries, but it also extends to gas gathering systems in the form of pipelines. These sunk infrastructure investments have enabled several companies to greatly reduce capex; reduced capex has, in turn, allowed some companies to turn free cashflow positive in recent quarters.

Furthermore, many companies have built out their own water handling infrastructure during this downturn. Operators in the Bakken often pay significant fees for water hauling and disposing to third parties. And Permian basin wells are notoriously known to produce vast amounts of water. This downturn has allowed some of these operators to build out the infrastructure to haul more water themselves, thereby reducing cost.

As service prices continue to rise, sand prices and pressure pumping costs could face the sharpest price increases. Sand and pressure pumping are key at this juncture because over the past two years operators have come to use increased concentrations of sand per lateral foot to boost well productivity. The increased volumes of sand and fluid require additional horsepower to pump downhole. However, material improvements in well performance suggest that many operators will be able to offset cost increases with increased oil production.

\section{Techniques and technological advances - reducing frack waste}

Although it can be argued that there have been no transformative technological gains during the downturn, it is clear that E\&P methodology and the application of technology has made great strides. The science and understanding of completion designs, well spacing, and the emphasis being placed on rock analysis and proper lateral placement are all contributing to well productivity gains. Operators are claiming that they have a better understanding of the reservoirs upon which they drill and are

\footnotetext{
${ }^{10}$ Most notably completion costs.

${ }^{11}$ Many operators were locked into rig contracts and would have paid a penalty to cancel their contracts.
} 

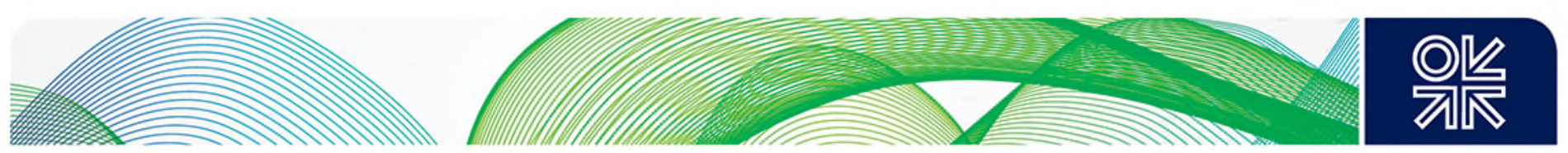

honing their placement of laterals to stay in precise pay zones. This would not only result in higher initial production rates but also higher EURs (Estimated Ultimate Recovery) and flatter tails.

There is also a conceptual change taking place as operators gain more knowledge of the reservoirs and see real productivity gains by implementing new spacing, lateral placement, and frack designs. Operators no longer want their fractures to extend as far as possible, rather, they want to keep them close to the wellbore so they can better drain the oil from the reservoir and rock closest to the lateral (wellbore) and place another lateral nearby to do the same thing. This means that companies are increasing reserves and drilling locations by being able to place more laterals closer together. As they become more comfortable with the idea that the wells are not communicating with each other (one well's fractures not draining another well's fractures, for example) they can place more wells in each section, increasing reserves and drillable locations. The plays that have hosted much of the drilling activity since this downturn, such as the Permian basin, are seeing incredible reserve increases by individual operators.

Completion designs and fracking methods are also changing. While the completion process and composition is complex, operators can use cheaper proppants and fluids by simply trying to stay closer to the wellbore, because they are not trying to carry the proppant out as far - they are essentially fracking and breaking up the rock nearest to the wellbore. Operators can use sand and a simpler fluid, such as slickwater, instead of a gel or hybrid to fracture and complete their well. This, along with cheap sand prices, has compelled many companies to use sand instead of ceramic or resin-coated sand for proppants. The low price of sand has also driven companies to use millions of pounds of sand per well, dramatically increasing initial production rates for some companies, but also increasing the overall well performance for many others.

At the heart of these completion changes is a growing knowledge of the reservoir. However, not every company has the capital resources to pursue rock analysis to study geology, petrophysics, and depositional environments, referred to as G\&G (Geological and Geophysical) investments by operators. But a great deal of this comes from company management and execution. Realistically, most companies should have had a substantial amount of in house rock data collected, but it was not necessarily processed and analysed during the rush at the height of the boom. What this price collapse has done is to light a fire under companies to better understand the geology and composition of the rocks in their acreage, so they can accurately map the best parts of the reservoir and try to place their laterals and fracture treatments more accurately in zone. Prior to the downturn, service companies such as Schlumberger noted that only 40 per cent of the fractures along a given wellbore were actually contributing to production. That meant that 60 per cent of those fracture treatments were wasted, in terms of well productivity and well cost. By accurately fracking and treating these wells, companies have increased production and reduced frack waste downhole.

Many independent shale players, both small and large, have tried to keep pace by mimicking some of the completion designs of their larger, highly productive peers. However, they often do so without necessarily performing the same level of rock analysis. Their lateral placement may not yield the same level of oil production increases, even with the same completion method, without proper G\&G research.

\section{Conclusion}

Many of those who were sceptical of US shale operators viewed high grading and the seemingly simplistic approach of increasing sand volumes as a sign that productivity gains had run their course. As data emerged that suggested better well performance on average, many of these sceptics rightly claimed that these companies were drilling fewer wells overall and that the wells that were being drilled were in better acreage, so naturally the curve would shift upwards. 

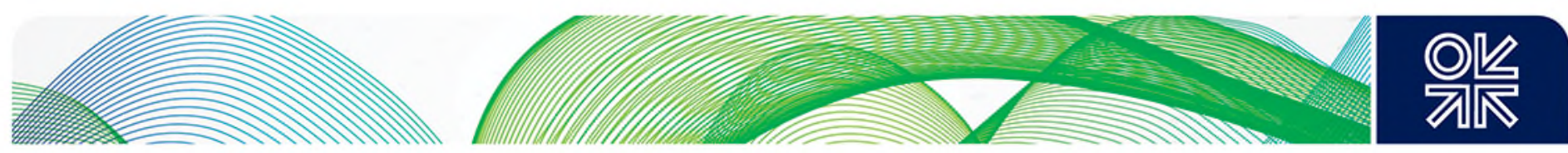

However, what these sceptics missed is the combination of the many subtleties stated above. There has been no single transformative technological development or epiphany with regards to shale oil development over the past several years. But there are signs that shale oil is moving from a manufacturing process, in which producers simply repeat what worked on the previous well (this worked to an extent as hardly any shale company drills a dry hole), to a more thoughtful, well researched programme.

Producers have not only capitalized on lower well costs by pocketing the savings. They are taking advantage of lower costs to improve rock knowledge and to explore additional production techniques. By better understanding the rocks, companies are able to place laterals in the most productive part of a reservoir's supposed payzone. By fracking closer to the wellbore and monitoring those fractures, companies are able to maximize the value of their fracture treatments, increase oil production and well productivity, and place laterals closer together. This in turn decreases the distance (in feet) between each well and increases the number of wells an operator can drill in their acreage, increasing drillable locations and reserves. These moves are being driven by the top producers in the shale oil arena, but they are being copied by their smaller counterparts with some success. High grading should no longer be viewed solely as a negative or limiting factor. Throughout this downturn, companies have proved up their acreage, substantially increasing the size and depth of what many thought were the existing 'sweet spots' and 'cores' of these plays. And while some companies might be overdoing the sand loading, with tens of millions of pounds of sand being pumped down a single wellbore, the step change in frack designs - keeping the fracks closer - has meant that these high intensity completions are paying off.

The shale oil sector is becoming far more resilient and nimble than many had expected. Productivity continues to grow in a poor economic environment and there is a lot of running room left in these unconventional oil plays. Should oil prices refuse to move markedly higher, more operators will likely sell assets or declare bankruptcy and more pain will be felt. However, more assets will also change hands, opening up the opportunity to apply new technology and methodologies to existing production. As Schlumberger stated, there is much room for productivity gains even if there are few remaining avenues to drive well costs down. But in a constant or slightly decreasing cost environment, any productivity gains represent a net increase in well efficiency and a decrease in production cost per barrel. 